\section{Endoscopic removal of an ingested toothbrush}

A 17-year-old female student reported that a piece of meat she had swallowed after chewing had become impacted in the region of the hypopharynx. After unsuccessfully attempting to remove the piece of meat with her fingers, she tried to dislodge it using an adult toothbrush, which measured about $18 \mathrm{~cm}$. However, both the piece of meat and the toothbrush slipped down her esophagus. The patient reported mild nausea and chest pain of short duration. Thoracic and abdominal $\mathrm{X}$-rays demonstrated bristles in parallel rows in the stomach ( $\boldsymbol{\bullet}$ Fig. $\mathbf{1})$. About 10 hours later, the patient had an endoscopy under intravenous sedation with midazolam ( $5 \mathrm{mg}$ ) and fentanyl citrate ( $78.5 \mu \mathrm{g})$. It showed a toothbrush head with bristles in the gastric body, with the rest of the toothbrush impacted in the pylorus (৫ Fig.2). An attempt was made to remove the toothbrush first with a foreign body forceps. The brush was dislodged from the pylorus, which facilitated its removal with a polypectomy snare without injury to the stomach or esophagus. The fingers had to be used to remove the toothbrush from the pharynx.

Ingestion of foreign bodies in adults is most often associated with mental disorders, bulimia, alcoholism, and as a way to initiate vomiting. Only a few cases of swallowed toothbrushes have been reported [1-5]. Because toothbrushes are long and rigid objects, it is difficult for them to spontaneously pass through the duodenum due to its fixed retroperitoneal position, or through the ileum, which may lead to perforation. In these cases a laparoscopic approach is an option $[1,2,4]$. For this reason, early diagnosis should be established and endoscopic removal should be carried out. X-rays, abdominal computed tomography (CT), and esophagogastroduodenoscopy are the main diagnostic methods. Characteristically, the bristles - in parallel rows - are observed on X-ray. Early endoscopic retrieval is usually successful and can be performed under intravenous sedation $[2,3]$.

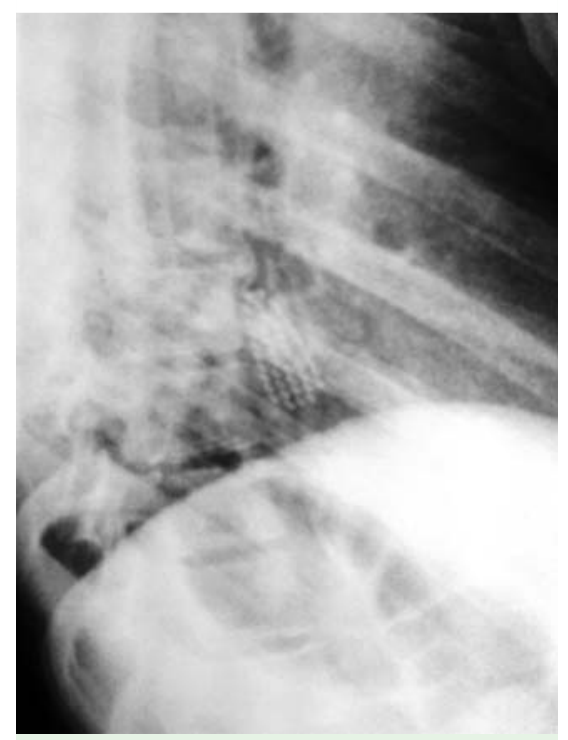

Fig. 1 X-ray showing bristles of a toothbrush in parallel rows in the stomach of a 17-year-old female student.

\section{Endoscopy_UCTN_Code_CCL_1AB_2AF}

\section{Competing interests: None}

\section{A. R. Gomes Jr}

Faculdade de Medicina do ABC, Gastroenterology Department, Santo André, Brazil

\section{References}

1 Sewpaul A, Shaban F, Venkatasubramaniam $A K$ et al. The case of the forgotten toothbrush. Int J Surg Case Rep 2012; 3: 184-185

2 Tonkic A, Bogdanovic Z, Grandić L. Successful endoscopic removal of a swallowed toothbrush: Case Report. Case Rep Gastroenterol 2011; 5: 122-124

$3 \mathrm{Lu} X \mathrm{X}$, Cao HL, Qian KD. Endoscopic removal of an accidentally swallowed toothbrush. Intern Med 2008; 47: 1797-1798

4 Chao HH, Chao TC. Perforation of the duodenum by na ingested toothbrush. World J Gastroenterol 2008; 14: 4410-4412

5 Saxene AK, Ainoedhofer H, Schalamon J. Retrieval of an ingested toothbrush in a 16 year old girl. Dig Surg 2007; 24: 477-478
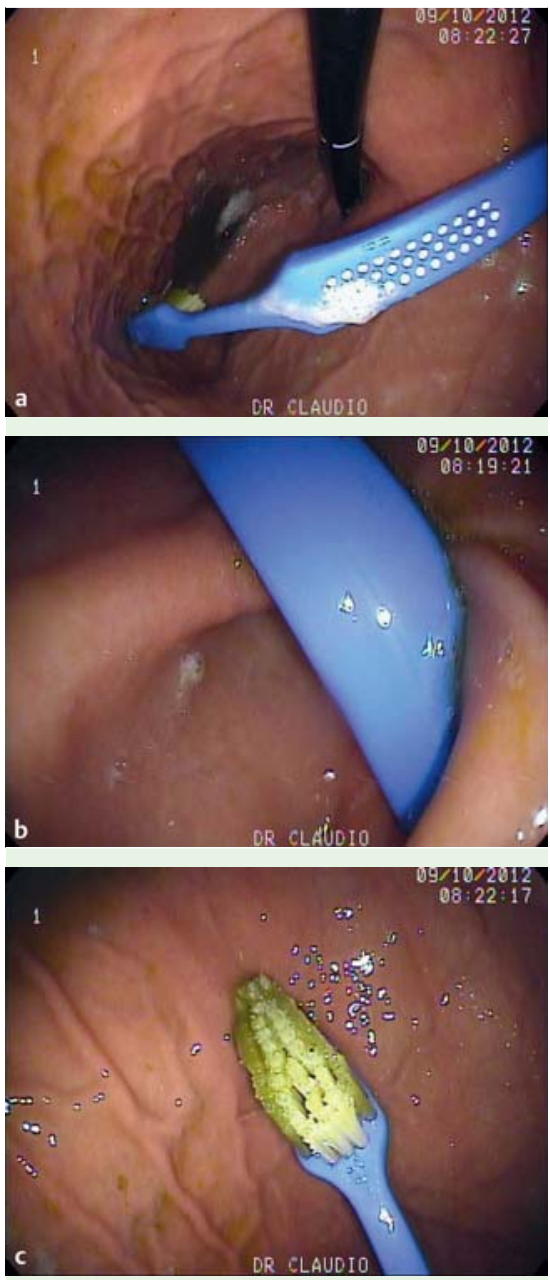

Fig. 2 a Retrograde endoscopic view of the toothbrush in the stomach. b The toothbrush impacted in the pylorus. c Endoscopic view of the toothbrush, with the bristles in the gastric body.

\section{Bibliography}

DOI http://dx.doi.org/

10.1055/s-0032-1326374

Endoscopy 2013; 45: E129

(c) Georg Thieme Verlag KG

Stuttgart · New York

ISSN 0013-726X

\section{Corresponding author}

\section{A. R. Gomes Jr, MD, PhD}

rua Xingu, 175 ap 51 santo André

São Paulo

Brazil 09060050

Fax: +5511-28965918

rufinogomes@terra.com.br 